\title{
Professional Ethics as Experienced by Student Teachers: A Neoliberal View
}

\author{
Marita Cronqvist, University of Borås, Sweden \\ Email: marita.cronqvist@hb.se
}

\begin{abstract}
Student teachers' experiences of professional ethics, as lived practice, need to be visualized and verbalized to support their ability to develop an ethical practice. The aim of this article is to discuss the lived experiences of professional ethics from beginning teachers' internship, based on a phenomenological study. Some of the essential meanings are interpreted in relation to the tension between responsibility and accountability that is emerging from neoliberal influences in teacher education. Inspired by Reflective Life World Research (RLR), interviews were conducted with student teachers specializing in preschool and elementary school. The empirical data was analyzed in order to determine the meanings that constitute the lived experience of professional ethics for early career teachers. By identifying the implications of professional ethics in neoliberal times, teacher educators can more easily observe and communicate the manifestations this has for teaching. Discussions and observations of professional ethics can stimulate student teachers' learning as part of teacher education discourse.
\end{abstract}

Keywords: professional ethics, teacher education, internship, life world, ethics, neoliberalism.

\section{Introduction}

In the phenomenological study of professional ethics (Cronqvist, 2015), ethics and morals were explored when student teachers in Sweden meet children as part of their teaching. Teaching ethically is the focus in this article, in effort to model and practice different ways to exercise professional ethics. The difference between teaching ethics and teaching ethically (Osguthorpe, 2008) is crucial. Teaching ethics might include explanations of what ethics means, understandings of right and wrong, different ethical views or how children should behave. This is something totally different from being an ethical role model, the professional trying to act respectfully and confidently as an exemplar.

Murrell, (2010) states that the act of teaching is a moral practice and extending this orientation, Fenstermacher (1990) describes the teacher's moral character as all encompassing: 
Nearly everything a teacher does while in contact with students carries moral weight. Every response to a question, every assignment handed out, every discussion on issues, every resolution of a dispute, every grade given to a student carries with it the moral character of the teacher. (p. 134)

However, it is not obvious that a moral orientation is inherent for teaching in the Swedish school system. Developing knowledge can be separated from developing values, and this view contributes to overlooking the importance of professional ethics in teaching. The emergence of neoliberalism in Swedish society has influenced a view of teaching as objective work, controlled by others and with reduced teacher autonomy (Englund \& Solbrekke, 2015; Nilsson Lindström \& Beach, 2015). During the last two decades, neoliberalism has come to dominate school policy in Sweden and the consequences for teachers are a focus on performativity, accountability and individual competition among schools and student academic success (Englund \& Solbrekke, 2015; Nilsson Lindström \& Beach, 2015). Englund and Solbrekke (2015) point to problems in the development of the education system where confidence in the measurability (accountability) gets priority over the confidence in the professional liability (responsibility) in order to substantiate the quality of teaching.

Neoliberalism has resulted in a singular focus, a priority of measurability in the Swedish school system. This development certainly has several explanations but one can be poor results in international surveys, reported by the Programme for International Student Assessment (PISA) (OECD, 2015). Wiborg (2013) describes the development from state to municipal governance and the emergence of the system with independent schools ${ }^{1}$ and this has created a situation where schools are in competition and the students are customers. In order to get customers, schools need to advertise their qualities, which are most obvious within measurability standards (see for example, Fjellman, Yang Hansen, \& Beach, 2018). In an inquiry involving teachers in Nordic countries, Carlgren and Klette (2008) questioned how governmental reform policies during the 1990s had affected teachers' work and they indicated that teachers in Sweden were clearly affected by demands for increased results and performance, revealing the impact of neoliberalism.

In the Swedish neoliberal context, knowledge is separated from relationships and feelings, and teaching has come to be understood as something neutral and objective. The consequence is that teaching ethics (different to teaching ethically) sometimes takes place on separate occasions, when learning is only about values and not about specific knowledge goals. This is often called values work which makes teaching ethics more aligned with the accountability regime since you can report and measure such exercises (Englund \& Solbrekke, 2015). According to Englund and Solbrekke (2015), both logics, accountability and responsibility, interact but the division provides the opportunity to discuss how they should be balanced in the development of teaching quality. Professional ethics needs to be further examined to understand what it means for becoming teachers and the impact that professional tensions, emerging from neoliberal demands, have on ethical practice.

\section{Ethics as Inherent}

As Husserl (1978) states, everyday life is lived through the natural attitude, thus experiences and their generated meanings are taken for granted. The phenomenological study on professional ethics (Cronqvist, 2015) is related to life world theory and the educational activity as a process of life worlds constantly being shaped and reshaped. Student teachers' awareness of choices and how choices are made in different situations is based on the individual's lifeworld and the impact on the lifeworld that the teacher education may have. Professional ethics is defined as inherent and implied in practice (Todd, 2008). However,

\footnotetext{
${ }^{1}$ Independent schools are not run by the public sector, but are mainly funded by tax credits
} 
ethics often remains unarticulated as inherent in a teachers' practice, and ethics, conceptually, needs to be discussed in order to help all teachers reveal the tacit in practice as they deal with complex scholastic situations (Orlenius \& Bigsten, 2013). Polanyi (1983/1966) argues, that "tacit knowledge" can be expressed, and different terms, for example "tact" (van Manen, 1995) or "phronesis" (Aristotle, 1993/1967) can be used to understand this knowledge. Professional ethics, as part of practical teaching skills, can be associated with Merleau-Ponty's $(2002 / 1945)$ concept of the lived body when knowledge is expressed in actions. Yet if actions are not reflected upon, the taken-for-granted is the result. Through reflections allowing selfawareness, daily situations and events unseen, can become conscious, and possible to study (Dahlberg, Dahlberg, \& Nyström, 2008). The visibility of professional ethics is needed to indicate qualities in teaching that are difficult to measure and in that way challenge neoliberalism. Therefore, it is crucial to verbalize professional ethics in practice (Colnerud \& Granström, 2002; Husu, 2003; Sockett \& LePage, 2002; Thornberg, 2008), and this begins by guiding beginning teachers to discuss and reflect on ethical dimensions associated with their life world. This entails a critical discourse in teacher education stimulating student teachers to learning to exercise professional ethics.

\section{Ethical Practice for Swedish Student Teachers}

To understand the struggle student teachers may experience in a neoliberal context, some aspects of learning professional ethics are briefly described and problematized. Modeling is a relevant strategy for student teachers' learning about professional ethics, as they too are becoming/being role models, learning through mentoring with supervisors during internship and on-campus, with professors, as part of their courses. In Swedish teacher education, supervisors are practicing teachers in preschools and schools who are responsible for the student teachers' education during the internship. Normally, the student teachers meet a few different supervisors during their education but they may have the same supervisor for several semesters.

The connection between the teachers' dispositions and children's development of morality is dependent on the teacher's role modeling (Carr, 2006; Osguthorpe, 2008). However, it is not clear what it means to be a role model: Is it necessary to be a virtuous person (Carr, 2006) or is it enough (and possible) to act as a role model only in the professional context (Osguthorpe, 2008)? According to Sanderse (2013), there is difficulty knowing if teachers are "good" role models and if their modelling efforts are effective. Sanderse (2013) is doubtful about whether teacher education is preparing student teachers to model; therefore, he raises demands to conceptualize and justify ethical role modeling. Research about how student teachers need to reflect on and develop dispositions during teacher education problematizes the meanings of becoming and being a role model (Sanger \& Osguthorpe, 2013; Schussler \& Knarr, 2013; Sockett, 2009). Uncertainty about the effect of modeling and identifying virtues makes it harder to predict the ideal of teaching ethically which gives neoliberal ideals of performance and measurement an advantage.

Van Manen (1995) connects modeling, judging and reflecting in the term "pedagogical tact," meaning "an active intentional consciousness of thoughtful human interaction" (p. 43). Hence, pedagogical tact is challenging educative praxis. To act tactfully means to watch children, understand their needs in the specific situation, and be able to act and respond appropriately. Pedagogical knowledge is largely embodied and inherent, and thus not based only on cognition. Therefore, feelings, intentions, morals, and beliefs are involved in the response. Pedagogical tact emerges spontaneously in situations where cognition is not enough. Modeling and judging, exist in ongoing practice in interactions with children. This means that relationships between children and between teachers and children require special 
attention in teacher education programs. Teague (2015) and Steinnes (2011) discuss the limits of cognition in teaching and the need for judgment in different situations - arguably ethical judgement. Teague (2015) explains that ethical relationships demand openness to the child in a particular situation. This openness requires a responsibility to be present and an awareness of not completely knowing the children in advance. Steinnes (2011) states it is the individual teacher who must make decisions with no guarantees about doing what turns out to be best or the right. Responsibility for making judgment lacks guidance or ethical conventions upon which to act in spite of conflicting perspectives that come with the complexities of teaching. Developing judgement and an ethical practice involves high demands on student teachers since preconceived notions about the children and predetermined strategies are often implied and assumed for teachers.

\section{Aim and Questions}

The empirical study about professional ethics (Cronqvist, 2015) focused on student teachers' lived experience from their internship. The aim was to investigate and provide an understanding of student teachers' professional ethics and its manifestation in practice. The questions concerning the meanings of professional ethics are as follows:

- How does professional ethics present itself to student teachers?

- How do student teachers deal with situations that present professional ethics?

The lived experience from the participating student teachers was formulated as essential meanings of professional ethics in practice. Some of these meanings are interpreted in relation to neoliberal demands in education.

\section{Methodology}

Through the approach Reflective Lifeworld Research (RLR), based on phenomenological epistemology (Dahlberg et al., 2008) knowledge about the essential meanings that constitutes a phenomenon is revealed. According to Dahlberg (2006), the essential meanings render the phenomenon's "style of being" (p. 18) explicit, and differentiate it from other phenomena. The phenomenon is contextual since it emerges in relation to a practice in the life world. When one's life world changes, the perception of the phenomenon changes. The experience of the phenomenon is also influenced by the people and how these people relate to the phenomenon. From all these different experiences of the phenomenon "professional ethics" an essential pattern of meanings that build upon the external differences was sought. The understanding of the phenomenon deepens when particular meanings are linked to general meanings (Dahlberg, 2006). To study how a person relates to a phenomenon, the result is based on the meeting between that person's perception of something and that of the researcher. This means that it is not possible, as a researcher to ignore their understandings or escape their own life world. As a consequence, it is crucial for the researcher to "bridle" (Dahlberg, 2006, p. 16) the way that understanding happens, and keep an open mind towards the phenomenon of study. Bridling, and "having an open mind" is like being a tourist in one's own hometown, when one is trying to see things in a new, different and surprisingly way (Dahlberg et al., 2008, p. 123).

\section{Participant Interviews}

The essential meanings were based on interviews with ten student teachers in Sweden: Nina, Eva and Ida were training for pre-school (age 1-6); Johan and Lena were specializing in Elementary school years 1-3 (age 7-9); Maria, Anna, and Stina were studying 
for Elementary school years 4-6 (age 10-12); and Lisa and Emma were preparing to teach special subjects in Elementary school, years 7-9 (age 13-15) (all names have been changed for confidentiality). Interviews were conducted from second to fourth semester (first and second year) immediately after the internship that ranged between two and four weeks. The selection of student teachers asked to participate was based on geographical location; thus, providing the possibility to follow several students at the same period. The interpretation of essential meanings in relation to neoliberalism is exemplified by data from Eva, Ida, Maria, Stina, and Lisa.

The phenomenological interview involves directing towards the phenomenon (Dahlberg et al., 2008) and in the study about professional ethics (Cronqvist, 2015) the participants were encouraged to tell about situations in their practice where ethics became important, according to the formulation of the phenomenon: morals and ethics in student teachers' encounters with children. The participants were asked to prepare for the interview in advance, helping them to move closer to the phenomenon; thus, they were more alert and willing to share their experiences during the interview. The strategy can be problematized through the distinction between experiences as instant (prereflective) or as reflected (van Manen, 2014). The purpose of the phenomenological interview is to capture the lived experience and not the participants' reflections or interpretations of the meanings of what they have experienced (van Manen, 2014). The interviews were open-ended and the interviewer bridled current understanding allowing the stories the participants told, which may be familiar, could still become subjects of curious follow-up questions (Dahlberg et al., 2008).

\section{Analysis and Results}

In RLR the analysis leading to the findings must be transparent and deliberative (Dahlberg et al., 2008). The analysis is conducted at different levels, and in different stages. Van Manen (2014) explains how meanings can be found in the interview as a whole, in separate paragraphs, or in detailed reading of sentences or words. The different stages entail that the researcher looks for meanings in the data and tries to find patterns in the meanings. In both these analysis processes, different parts of the data relate to the whole and the whole to the parts, to see if the patterns remain convincing. When a meaning is observed in data, it needs to be questioned and, as a researcher, I must deal with my intentionality, trying to determine if the data really indicates the meaning or if it comes only from my interpretation. The analysis is done over a long period of time, and the findings are discussed with colleagues. In these discussions, bridling and openness also support the researcher to be cautious, and to not formulate themes and conceptualize the phenomenon's meanings too quickly. Patience allows the phenomenon to present itself, and "to keep its indefiniteness as long as possible" (Dahlberg \& Dahlberg, 2003, p. 48).

The essential meanings of the phenomenon "professional ethics" are constituted by the following meaning elements:

- Ambiguity requires an approach to responsibility;

- External factors can be obstacles;

- Relationship and learning are interwoven;

- Experiences should be for a child's best interests;

- Every child must be included;

- Authority arises through an atmosphere of joy, respect and safety;

- Development occurs when theory and practice meet in reflection. (Cronqvist, 2015, p. 145)

The essential meanings constituting the phenomenon are different from each other, but appear together in practice, and are in that sense related to each other. Four of these essential 
meanings are presented and interpreted in relation to demands from neoliberalism and tensions between accountability and responsibility (Englund \& Solbrekke, 2015) ${ }^{2}$. The presentation starts with an abstract explanation of the meaning constituents, followed by an overview, which is a summary of how the essential meaning has appeared to student teachers. Then, concrete examples from student teachers' experiences with quotes from data are presented. Finally, the meanings are interpreted in relation to neoliberalism.

\section{Ambiguity Requires an Approach to Responsibility}

The essential meaning of professional ethics is to, despite ambiguous and complex situations, relate to responsibility for the children, to act or not to act, and take responsibility for the consequences. The approach to responsibility always means an uncertainty about the consequences. Uncertainty complicates the learning of professional ethics. An approach to responsibility means to balance and set limits of the ambiguous.

Overview. The ambiguity is experienced by student teachers in several ways, for example as differences between university courses and internship. They experience values in conflict within themselves and in relation to other people, mostly to the supervisor or the children. They also experience a difference of attitudes between expressing in words and in action.

Examples. Student teachers sometimes experience ambiguity when their own ideas of how to act are different from the supervisors' acting. Ida feels that her attitude towards the children is difficult to balance between being strict and allowing:

They [The children] started throwing stuffed animals, they have a huge basket and then they poured them out and they threw them at each other, then it was me and another girl who tried to take control so they would stop and then [the supervisor] said in retrospect that well, it did not matter, it was not the whole world really if they had continued, so we are a bit different also how we see it.

Ida's supervisors (now and during previous practice) are more allowing toward the children than herself. She says: "we have different views and so, they might be more permissive than what I am used to, has been at places before that have not been as tolerant." These different perceptions are good, Ida thinks, because she gets the opportunity to rethink her position. Ida's supervisors function as role models, meaning that they have similar values and basic views; therefore, learning becomes stimulated. Developing self-confidence as knowledge in concrete situations is crucial to pedagogical tact (van Manen, 1995).

Maria tells about a situation when a student said something unpleasant to the teacher and the teacher responded by giving a reprimand to another student who did not do anything in that situation. The student who received a reprimand started to cry and went away but the teacher did nothing to follow it up. Maria says: "I thought it was very strange that he [the teacher] personally did not respond to one of his students who had left crying because he had, what do you say, yelled at her." Maria experiences the situation as problematic because she does not get any explanations. Maria felt that she should go after the student and talk to her: "I feel that, that being a support and just see that OK, I have seen you, I see you are upset, I will try to help you in any way." Afterwards, when Maria has supported the student, she is worried about how her supervisor will react to her interventions. Maria is worried about this because she needs to be successful in her internship.

Compared to the neoliberal demand for a clear correct structure in teaching, both situations indicate the loneliness in judgement that Steinnes (2011) is describing. Ida and Maria made their own decisions based on how they understand the situation and their

\footnotetext{
${ }^{2} \mathrm{~A}$ presentation and interpretation of remaining meaning elements can be found on my blog
} (etiskundervisning.wordpress.com) 
children's needs. No ethical conventions can help and both student teachers are acting without supervisors' support. Without conventions, standards or a right way to act, neoliberal demands for measurement and performing become difficult to carry out.

Judgment, understood as pedagogical tact (van Manen, 1995), is a special kind of thoughtful and personal style of acting. The pedagogical tact entails that feelings and beliefs "take over" when knowledge is insufficient. Student teachers' feelings can make them act but not necessarily because they lack knowledge, but rather that the situation raises strong emotions about children's needs. When student teachers choose to support children, they are not always sure it is the most rational decision, but they feel they must do something. Feelings sometimes seem to be stronger than reason and even strong enough to go against the supervisors' authority. Solbrekke and Englund (2014) distinguish between rationality as moral (responsibility) and economic/legal (accountability). The student teachers' rationality could be understood as moral when their feelings take over.

If the supervisor does not function as a role model, the focus is on how and why the student teacher thinks differently and most often they are left wondering if their view or actions are acceptable. When this uncertainty arises, different views are experienced as problematic and it is not positive for learning when student teachers question themselves (van Manen, 1995). When the supervisor functions as a role model, critical reflections seem to provide learning. An understanding of differences creates a distance to the situation that leads to reflection and self-awareness and thereby stimulates development (Dahlberg et al., 2008; Gadamer, 1989). Both confidence and critical reflections are consequently exemplified as ways to develop teaching, depending on the supervisors' ability to serve as role models. When student teachers act on their feelings, it is a kind of confidence that they must follow their hearts, even if they fear consequences since they are still enrolled in an internship. This results in an ethical tension: student teachers are in a position where they are subject to external control, from supervisors and teacher educators at campus. This external control (accountability) needs to be balanced against the student teachers' possibilities to develop their own judgment (responsibility) in practice. Different life worlds can be one explanation to divergent views and a tension between student teacher and supervisor. When Ida prevents the children from throwing stuffed animals, one interpretation can be that the supervisor knows the children and feels confident to stop the activity when it is needed while the student teacher, not so experienced, perhaps is unsure of her ability to maintain control. In their judgment they see different dangers or possibilities based on prior experiences and knowledge, their life worlds as supervisor and beginning teacher. Since the supervisor in this case functions as a role model, the student teacher can reflect on the tension between them and learn from it.

\section{Relationship and Learning are Interwoven}

The essential meaning of professional ethics is that relationships to children and between the children and their ability to learn are interwoven in that knowledge, feelings and attitudes cannot be separated. Through dialogue with children about different attitudes and opinions, children learn, meaning that they develop new understanding. Children's needs are considered by getting to know them, and in that way, strengthen the possibilities to help them in their development and learning.

Overview. Student teachers have experienced that good relationships with children and between children stimulate learning, no matter what the knowledge content is about. Through dialogue, different opinions and perspectives are displayed and everybody involved learn together as they get to know each other. According to student teachers' experiences, knowing each other made it easier to tell one another about their different experiences. Not 
only through discussions, but also through facts, attitudes to others can be improved. The student teachers tell about how learning stimulates relations and that relations stimulate learning. Getting to know the children, knowing things about, for example, their background and interests facilitates teaching to motivate children and to meet them as they make progress. Explanations are important for different reasons, both as a help for children to understand why they must follow a rule and as guidance for student teachers to understand why children behave in a certain way. Student teachers perceive that when different circumstances are known, it is easier to understand and deal with problems. As children's needs are considered their learning process progresses.

Examples. Lisa tells about a discussion she experienced in one of the classes that she was visiting during her internship:

It was quite obvious after about forty-five minutes that he (a student) feels that other people are simply not his problem either in small or big, meaning locally or globally matters...he has no perception that other people feel and think and there it became obvious that you need to work with morals in direct teaching.

Lisa reflects on the situation and explains:

Curriculum nicely tells that students should be fostered and formed to responsible independent individuals in society, and so on and so on, and when this kind of case appears, you immediately feel that yes, we need to work with this, it is not just words, but actually real students who seriously think that other people are not worth anything.

Lisa experiences how her supervisor addresses the problem with students expressing indifference to other people. Lisa considers her supervisor as a role model for her future work: She handled it [the problem with students indifferent to other people] in the moment and worked with it and somehow involved lesson planning with what had happened so basic values and the school subject Swedish were not separated. Usually, they are handled separately. She drew them together in such an elegant way.

The essential meaning of professional ethics means that teachers must interweave knowledge content, relationships, emotions, attitudes and values. Just as Lisa expresses, it is common to work with values and subjects separately, probably as a consequence of an understanding that knowledge is mainly connected to cognition, not emotions and values. This understanding is related to a neoliberal, instrumental view of knowledge and learning (Mavelli, 2014; Solbrekke \& Englund, 2011). Knowledge is easier to measure if you keep it away from subjective aspects as feelings and attitudes. The supervisor's way to connect subject and basic values, to the students made Lisa see an alternative way to teach than the approaches offered by the neoliberal technical view.

Another example is given by Ida. She describes a situation when she experienced how her supervisor told a child to go and wash his hands:

Instead of just saying "go and wash your hands" she also tells him why he has to wash his hands, gives an explanation of things and has a discussion with children...it gives them [the children] an opportunity to understand and they learn why you need to wash your hands for example and that they can have a discussion, that they see the children as individuals.

This example shows how real dialogue and an explanation can help the child to understand and gain knowledge, for example health conditions, not just obey a teacher's orders. In both situations, the supervisors act as role models, and thereby, stimulate student teachers' learning. The personal understanding of knowing something that Ida exemplifies is to a great deal missing in the neoliberal view of learning as something that is easily measured and objective. Also, in this meaning the limit of cognition that for example Teague (2015) and van Manen (1995) point out is relevant. Researchers, studying ethics in education, are quite united that teaching is a moral matter (Murrell, 2010) and therefore, interweaving of learning and 
relationships must be preferred over a neoliberal view of teaching as performance.

\section{Every Child Must be Included}

The essential meaning of professional ethics entails a responsibility to include every child and to support everyone in participating. Each child must be invited to participate in learning no matter what difficulties this may cause. They should have the support they need to be able to participate. To include the children means to meet them in their progress which is challenging yet necessary. This essential meaning is close to the meaning of interweaving relationships and learning. The difference is that inclusion means a responsibility to support children's participation in their learning, while the other meaning is about interweaving relationships, knowledge content, emotions and attitudes in teaching. They are separate meanings of professional ethics, and relationships are important in both meanings.

Overview. Student teachers' experiences of inclusion are about children's possibilities to express opinions, to be involved in and control what happens during an activity or a lesson, and to have a say about different rules. The children's learning process indicates how they can be supported in their development.

Examples. Stina, who met several boys that struggled with concentration in their work, reflected on how it could be possible to include them in conversation. She says: "if there is some other way that more help the students and develop them instead, rather they are always...somehow it feels as if they do not develop since they always have that role." Stina experiences that it is important to try to break negative roles in the group in order to stimulate their participation. She tries different ways through asking questions, talking to them, inviting them to participate, and she perceives it is essential to try even if it is very difficult. Stina tells about how participation can depend on her competence to give the children tasks with different options. She says: "The same task can both have an easy and a difficult answer, but the students are not really aware that they are performing the difficult or the easy task, although they still do the same task." In neoliberalism, the individual performance is central and children that have difficulties to follow ordinary teaching are at risk of being left out (Hedegaard-Soerensen \& Grumloese, 2018). Stina is troubled about how to involve children who have difficulties to adapt to the expected behavior in the group. Troublesome and loud children are a common problem in teaching. When children are perceived as difficult based on previous experience, it is this image of the children, or that child in particular, becomes part of the teacher's life world and the natural attitude (Husserl, 1978) expanding the notion that children are troublesome. Unfortunately, many of these children get stuck in roles that they are unable to break.

This problem of predefined roles is raised by Teague (2015) when advocating ethical encounters through openness to children in each situation. Inclusion is a concept that has become problematic since the interpretation of it can contribute to exclusion. A common understanding of inclusion in empirical research about special education is participation of all children in the same classroom (Nilholm, 2006; Nilholm \& Göransson, 2017). Since the classroom is not adapted for all children, some of them might be academically and socially excluded when they have difficulties. This view of inclusion challenges teachers, as neoliberal pressures hold them accountable for each individual child's performance, and forces the questioning about student placement and gathering in the same classroom. Student teachers struggle trying to break children's negative roles, support them to participate and not reinforcing, accepting or cementing destructive roles. To the individual child, this struggle might be decisive to their development. Student teachers find it difficult to achieve full participation, but Stina has a helpful attitude to keep trying. 


\section{Development Occurs When Theory and Practice Meet in Reflection}

The essential meaning of professional ethics is to bring together theory and practice through reflection. In this way, professional ethics can be practiced and developed. When meeting children, experiences are made and things that did not work out can be merged with theories from education through reflection. Based on reflection, other ways of acting can be tried.

Overview. The student teachers told about experiences of how they reflected, but mostly used other words like "thinking about" They distinguish between just doing without thinking, because they must act in the moment, and how they afterwards reflect on the situation, and through reflection bring together their lived experiences with knowledge and theories from education.

Examples. Eva experienced how she learned when she had the opportunity to repeat her teaching efforts, reflecting on the situation and trying the activity again. Gradually, she noticed she was able to pay more attention to the children's needs. By performing in practice it became clear what it meant to let the children's needs come to the forefront. For Eva, reflection helps her to see her shortcomings and makes it clear that something can always be done better. She says: "I have spent much time to really write everything down and reflect on what I have done these... because I think it is important to learn not only in books but compare how it is in the books, how it is in the reality that you are trying to get one of these, try to bind together two or merge two." Writing allows Eva to catch sight of, and find herself in the role of the teacher. She says:

In the books, the children are an object, you do not have to react immediately so to speak when you write a text but in class you must react immediately, one thing is not easier than the other but it is two quite different ways to, for example, address children then and I think, I believe that through more exercise you manage to combine these things, to have in mind what I read in books, how to transform it in reality.

In this essential meaning, reflection connects the experienced situation in practice with an understanding of the situation when theories can be added. The ongoing process of development through reflection on theory and practice combined is important for Eva in her learning to become a teacher.

In a neoliberal culture, reliance on effective methods and structure takes precedence instead (Solbrekke \& Englund, 2014). Eva mentions that children are objects in the theory but in practice children have to be addressed with immediate reactions as subjects. In a neoliberal view, children are treated like objects, since they are valued based on their performance (Hedegaard-Soerensen \& Grumloese, 2018). To Eva, reflection on her teaching develops her abilities to attend to children's needs and feelings in practice. When student teachers are acting in situations, they sometimes feel compelled to make choices because something happens that they have not predicted. Judgment and pedagogical tact are based on knowledge, but also on feelings, intentions and beliefs (Aristotle, 1993/1967; Campbell, 2003; van Manen, 1995). Acting out of a place of feelings is common for student teachers, but most often they do not express that choices are based on knowledge, intentions or beliefs. Reflection is a possibility to develop professional ethics in teaching through awareness of one's own intentions, beliefs and to use knowledge in their judgment. Teacher education needs to support them in this.

Student teachers' learning can be understood as individual in the sense that experience is added to experience, but in teaching, different life worlds meet and interact and it is an open question when or if experiences are reflected (Burman, 2014). In order to develop professional ethics, with focus on responsibility, not letting accountability with ready-made 
solutions take over, it is crucial for student teachers to be aware of what beliefs and values they want to act on and how these beliefs and values are consistent with the child's best interests, collegial agreements, curricula and laws. The UN Convention on the Rights of the Child claims that the child's best interest should be the primary consideration but this claim, as many other statements in curricula and laws, is problematic. The statements are abstract and need to be interpreted in the life world of practical teaching. The space of interpretation makes it crucial for student teachers to develop professional ethics during teacher education and further on, in order to emphasize responsibility before accountability.

\section{Discussion}

In the empirical study about professional ethics (Cronqvist, 2015), student teachers shared their lived and reflected lived experiences from internship and through analysis, the essential meanings were formulated, allowing ethical practice to become verbalized and visible. Professional ethics is not measurable in a way that is demanded from a neoliberal point of view, but must be made visible and verbalized in order to get attention in teacher education (Colnerud \& Granström, 2002; Husu, 2003; Sockett \& Le Page, 2002; Thornberg, 2008). Van Manen (1995) expresses that teaching is an embodied knowledge that phenomenology can be used to put words to. Thus, student teachers get opportunities to become aware of ethical practice, discuss it, learn it and to clarify its importance. The challenges that arise from tensions between responsibility and accountability in a neoliberal education system are discussed in relation to the essential meanings and student teachers' learning to teach ethically.

\section{Tensions Between Responsibility and Accountability}

The meanings of professional ethics as a whole mostly correspond with responsibility, rather than accountability, and responsibility is difficult to capture. One of the difficulties is that ambiguity that requires an approach to responsibility, allows for several ways of acting. In a neoliberal education system ambiguity is problematic since teachers' work becomes difficult to measure. In the struggle of student teachers, the balance can be between using effective methods or appropriate strategies and the need to deal with the current situation without one "right" answer. Judgment becomes contradictory to conventions and instead, creativity is wanted (Steinnes, 2011). One way to understand creativity is the ability to meet the children without predictions, in a way that enables them to develop and not get stuck in permanent and destructive roles. The narratives from student teachers about the situations show that they acted not primarily based on knowledge, but from feelings for the children, related to their heart. This contradicts the dominant view of neoliberalism and maybe responsibility can get more attention if we learn to express it verbally. A balance between the logics must allow judgment (Englund \& Solbrekke, 2015).

In some situations, student teachers must deal with children expressing attitudes that are not consistent with curricula. The neoliberal ideal about objective, true and measurable knowledge, separated from feelings and attitudes, makes it possible to ignore when children express themselves inappropriately. Furthermore, in the neoliberal educational context in Sweden, children and their parents are viewed as customers, who must be satisfied otherwise the school can lose funding (Wiborg, 2013). Thus, different values at home and in pre/school can be difficult to handle. However, when student teachers or supervisors deal with the children, and continuously conduct a dialogue about values with them, responsibility is taken.

The essential meaning of professional ethics to include children, entails a struggle 
with a culture characterized by prescribed attitudes, beliefs and actions. To student teachers, feeling an urgency to support children to participate and be involved, such a neoliberal culture makes it difficult for them to exercise professional ethics (Cronqvist, 2015; Young \& Foran, 2017). A neoliberal focus on individual performance is preferred over children's needs for community and security. The tension is between judgment in relation to the current situation, the children's needs and a preconceived idea. The student teachers tell about how they experience the tension themselves, but even very experienced teachers sometimes create a culture where both actions and attitudes to children are settled in advance (HedegaardSoerensen \& Grumloese, 2018). Maybe this depends on their work having developed into a routine that they do not question because it has become a part of their natural attitude (Husserl, 1978). Since the children are not known to the student teachers, they pay attention to these permanent roles and are sometimes questioning them and wanting to change them.

When theory and practice are brought together by reflection, predetermined strategies and prescribed views of how children function can be counteracted. Student teachers struggle between knowing for sure (accountability) and an uncertain approach towards children as an openness (responsibility) that Teague (2015) is proposing. The case of not knowing and having to meet children with openness, becomes difficult to defend in neoliberal times. For a student teacher, perhaps not especially experienced and self-confident, it may be difficult to make choices in the situation. Deciding in advance, relying on effective methods and thus gaining control may be preferable. Through such a need for control, accountability becomes contradictory to responsibility, required by professional ethics. Issues of knowledge, beliefs and intentions need to be further discussed and reflected, to give the situated judgment (responsibility) precedence over the standardized approach (accountability).

\section{Learning to Teach Ethically in a Field of Tension}

Student teachers' learning to teach ethically takes place in the field of tension between responsibility and accountability. Learning responsibility involves self-awareness, an understanding of values and intentions in teaching, how to function as a role model and ability to exercise judgment in practice (Sanger \& Osguthorpe, 2013; Schussler \& Knarr, 2013; Sockett, 2009). In the learning process, reflections are crucial and need to be developed. Student teachers' awareness of their life worlds in teaching makes their weaknesses visible and possible to deal with during education. The neoliberal view of teaching as objective work (Nilsson Lindström \& Beach, 2015) questions the importance of student teachers' life worlds and the need to develop self-awareness.

Neoliberal practices also provoke student teachers' need to understand their intentions in teaching. Since it is not clear how relationships and attitudes can be a natural part of teaching (Campbell, 2003, van Manen, 1995), student teachers need to practice to express intentions both with content and with values. Van Manen (1995) states: "tact can refer both to the intersubjective pedagogical relation between teacher and child as well as to the hermeneutic didactical relation between teacher and curriculum content or knowledge" ( $p$. 44). This is an expression that supports the idea of interweaving learning, relationships and feelings.

Learning is also depending on whether the supervisor is regarded as a role model and basic values are shared, or not. When the supervisor does not function as a role model, student teachers sometimes are left with all their questions on their own. In the study, there are examples of how student teachers perceive their beliefs and values both in contradiction and accordance with the supervisors. A problem is that the supervisor, not functioning as a role model, still is an authority. The student teacher is dependent on approval from the supervisor. If the student teacher is forced to act in accordance to the culture that the supervisor 
is part of, the judgment is hampered and accountability takes precedence. The combination of student teachers' uncertainty and supervisors' established routines makes it difficult to question approaches in experienced situations and in this way, accountability can be an obstacle to student teachers' learning. The tension can be described as a balance between embracing the supervisor's teaching as prescribed without questioning it (accountability) and being critical, wanting to be creative and develop an own approach (responsibility).

When supervisors are perceived as role models, student teachers express that the supervisors are present in the situation, "read" the children's needs and build relationships to the children by asking them about their situation both at home and in pre-school (Cronqvist, 2015). These descriptions correspond largely with pedagogical tact (van Manen, 1995) and emphasize the importance of judgment which is part of student teachers' learning to teach ethically. The openness to children's differences is part of being present. Tact (van Manen, 1995) and phronesis (Aristotle, 1993/1967) are abilities to exercise professional ethics, when ambiguity requires an approach to responsibility. Practicing pedagogical tact or phronesis, seeking the best choice in the situation must always be intentional: what is the best for the child despite pedagogical differences among those involved addressing what is best.

The findings include an example of a tension between a student teachers' possibility to control the children and children's take over. The children's needs can be contradictory meaning that the best for one child may not be best for all. In this kind of dilemma, where it may not be possible to find a "good solution;" thus, responsibility is preferred over accountability, and critical here is that student teachers need to discuss these situations. Student teachers need support to develop their judgment and courage, because teaching can be lonely as they are going to be to make choices on their own (Steinnes, 2011). Tact (van Manen, 1995) and phronesis (Aristotle, 1993/1967) also mean an opportunity for change, to use imagination and act in new ways. Among student teachers, there are ideas about how they want to try other ways but there are not always possibilities or allowance to implement them (Cronqvist, 2015). The point is that student teachers sometimes cannot practice their sense of responsibility. Their sensitivity to the situations and judgment is not developed, meaning that they sometimes have to be content by reflecting on strategies and not always being able to try them. The differences and tensions in this discussion between student teachers' experiences of situations and supervisors' acting indicate some interesting possibilities and challenges to integrate professional ethics in teaching. Hopefully, this study can contribute to an understanding of what professional ethics means and support future pedagogical discussions about how it can be implemented and learned.

\section{References}

Aristotle. (1993/1967). Den nikomachiska etiken. 2 uppl. Göteborg: Daidalos.

Burman, A. (ed.). (2014). Den reflekterade erfarenheten: John Dewey om demokrati, utbildning och tänkande. Huddinge: Södertörns högskola.

Campbell, E. (2003). The ethical teacher. Buckingham: Open University Press.

Carlgren, I., \& Klette, K. (2008). Reconstructions of Nordic teachers: Reform policies and teachers' work during the 1990s. Scandinavian Journal of Educational Research, 52(2), 117-133, DOI: 10.1080/00313830801915754 
Carr, D. (2006). Professional and personal values and virtues in education and teaching, Oxford Review of Education, 32(2), 171-183.

Colnerud, G., \& Granström, K. (2002). Respekt för läraryrket: om lärares yrkesspråk och yrkesetik. [New, rev. and updated version.] Stockholm: HLS förl.

Cronqvist, M. (2015). Yrkesetik i lärarutbildning - en balanskonst. Diss. Göteborg: Göteborgs universitet, 2015. Göteborg.

Dahlberg, H, \& Dahlberg, K. (2003). To not make definite what is indefinite: A phenomenological analysis of perception and its epistemological consequences in human science research. The Humanistic Psychologist, 31(4), 34-50.

Dahlberg, K. (2006) The essence of essences - the search for meaning structures in phenomenological analysis of life world phenomenon. International Journal of Qualitative Studies on Health and Well-being, 1, 11-19.

Dahlberg, K., Dahlberg, H., \& Nyström, M. (2008). Reflective lifeworld research (2nd ed.) Lund: Studentlitteratur.

Englund, T., \& Solbrekke, T.D. (2015). Om innebörder i lärarprofessionalism. Pedagogisk forskning $i$ Sverige, 20(3/4), 168-194.

Fenstermacher, G. D. (1990). Some moral considerations on teaching as a profession. In J. I. Goodlad, R. Soder, \& K. A. Sirotnik (Eds.), The moral dimensions of teaching (pp. 130-151). San Francisco: Jossey-Bass.

Fibæk Laursen, P. (2004). Den autentiska läraren: bli en bra och effektiv undervisare - om du vill. 1. uppl. Stockholm: Liber.

Fjellman, A-M., Yang Hansen, K. \& Beach, D. (2018). School choice and implications for equity: the new political geography of the Swedish upper secondary school market, Educational Review, 71(4), 518-539. DOI: 10.1080/00131911.2018.1457009

Gadamer, H-G. (1989). Truth and method. (2. revised edition). [Wahrheit und Methode]. (Transl. J. Weinsheimer \& D.G. Marshall). London: Sheed and Ward.

Hedegaard-Soerensen, L. \& Grumloese, S. P. (2018): Exclusion: the downside of neoliberal education policy. International Journal of Inclusive Education, 24(6), 631-644 DOI: $10.1080 / 13603116.2018 .1478002$

Hultman, G. (2001). Intelligenta improvisationer: om lärares arbete och kunskapsbildning $i$ vardagen. Lund: Studentlitteratur.

Husserl, E. (1978[1970]). The crisis of European sciences and transcendental phenomenology: An introduction to phenomenological philosophy. Evanston: Northwestern University.

Husserl, E. (1995). Fenomenologins idé. 2. uppl. Göteborg: Daidalos. 
Husu, J. (2003). Constructing ethical representations from the teacher's pedagogical practice: A case of prolonged reflection. Interchange, 34(1), 1-21.

Mavelli, L. (2014) Widening participation, the instrumentalization of knowledge and the reproduction of inequality. Teaching in Higher Education, 19(8), 860-869.

Merleau-Ponty, M. (1968). The visible and the invisible. Evanston: Northwestern University Press.

Merleau-Ponty, M. (2002[1945]). Phenomenology of perception. London: Routledge.

Murrell, P. C. (ed.). (2010). Teaching as a moral practice: Defining, developing, and assessing professional dispositions in teacher education. Cambridge, Massachusetts: Harvard Education Press.

Nilholm, C. (2006). Inkludering av elever "i behov av särskilt stöd” [Elektronisk resurs] : vad betyder det och vad vet vi?. Stockholm: Myndigheten för skolutveckling.

Nilholm C., \& Göransson, K. (2017). What is meant by inclusion? Analysis of European and North American journal articles with high impact. European Journal of Special Needs Education, 32(3), 437-451, DOI: 10.1080/08856257.2017.1295638

Nilsson Lindström, M., \& Beach, D. (2015). Changes in teacher education in Sweden in the neo-liberal education age: Toward an occupation in itself or a profession for itself? Education Inquiry, 6(3), 241-258.

OECD. (2015). Improving schools in Sweden: An OECD perspective. Paris: OECD

Orlenius, K. \& Bigsten, A. (2013). Den värdefulla praktiken: yrkesetik i pedagogers vardag. 2. uppl. Stockholm: Liber.

Osguthorpe, R. D. (2008). On the reasons we want teachers of good disposition and moral character. Journal of Teacher Education, 59(4), 288-299.

Pence, G. (1997). Virtue theory. In P. Singer (Ed.), A companion to ethics (249-258). Oxford: Blackwell Publishers.

Polanyi, M. (1983[1966]). The tacit dimension. Repr. Gloucester, Mass.: Peter Smith

Sanderse, W. (2013). The meaning of role modelling in moral and character education. Journal of Moral Education, 42(1), 28-42.

Sanger, M. N. \& Osguthorpe R. D. (2013). Modeling as moral education: Documenting, analyzing, and addressing a central belief of preservice teachers. Teaching and Teacher Education, 29, 167-176.

Schussler, D. L., \& Knarr, L. (2013). Building awareness of dispositions: enhancing moral sensibilities in teaching. Journal of Moral Education, 42(1), 71-87.

Sockett, H. (2009). Dispositions as virtues: The complexity of the construct. Journal of Teacher Education, 60(3), 291-303. 
Sockett, H., \& LePage, P. (2002). The missing language of the classroom. Teaching and Teacher Education, 18(2), 159-171.

Solbrekke, T., \& Englund, T. (2011). Bringing professional responsibility back in. Studies in Higher Education, 36(7), 847-861.

Solbrekke, T., \& Englund, T. (2014). Certification of teachers: Tensions in a New Signature Reform. Professions and Professionalism, 4(2), 1-13.

Steinnes, J. (2011). The knight of faith: Ethics in special needs education. Journal of Moral Education, 40(4), 457-469.

Teague, L. (2015). Acceptance of the limits of knowability in oneself and others: performative politics and relational ethics in the primary school classroom. Discourse: Studies in the Cultural Politics of Education, 36(3), 398-408.

Thornberg, R. (2008). The lack of professional knowledge in values education. Teaching and Teacher Education, 24(7), 1791-1798.

Todd, S. (2008). Att lära av den andre: Levinas, psykoanalys och etiska möjligheter $i$ undervisning och utbildning. Lund: Studentlitteratur.

van Manen, M. (1995). On the epistemology of reflective practice. Teachers and Teaching: Theory and Practice, 1(1), 33-50.

van Manen, M. (2014). Phenomenology of practice: Meaning-giving methods in phenomenological research and writing. Walnut Creek, California: Left Coast Press.

Wiborg S. (2013). Neo-liberalism and universal state education: the cases of Denmark, Norway and Sweden 1980-2011. Comparative Education, 49(4), 407-423, DOI:10.1080/03050068.2012.700436

Young, D., \& Foran, A. (2017). Partnership in developing professional identity. In Blessinger, P., \& Cozza, B. (Eds), University partnerships in higher education (237-253). New York: International HETL Association. 